\title{
PROPORSI DAN STRUKTUR TOKOH KSATRIA PADA WAYANG KULIT PURWA GAYA SURAKARTA
}

\author{
Indah Nur Syahida ${ }^{1)}$, Pandu Ramadhan ${ }^{2)}$, Dendi Pratama ${ }^{3)}$ \\ Program Studi Desain Komunikasi Visual, \\ Fakultas Bahasa dan Seni, Universitas Indraprasta PGRI \\ Jl. Nangka No. 58c, Tanjung Barat, Jakarta Selatan, 12530, Indonesia \\ indahnursyahida03@gmail.com
}

\begin{abstract}
Abstrak
Wayang sebuah warisan budaya yang adiluhung. Keagungan filosofi dan keindahan tatahan serta sunggingan kesenian wayang ini sudah mendapat pengakuan dunia. Wayang Kulit Purwa terutama pada tokoh ksatria bila diamati lebih dekat, maka akan terlihat detail visual grafis yang mengagumkan. Nilai pada karakter setiap tokoh yang ada sangat mencerminkan budaya Jawa melalui cerita dalam pagelaran wayang kulit purwa. Dalam artikel ini akan dibahas mengenai Tokoh ksatria beserta proporsi dan struktur bentuk tubuh wayang purwa gaya Surakarta yang memiliki ciri khas atau perbedaan mendasar, antara lain memiliki ukuran lebih tinggi satu palemanan daripada ukuran wayang kulit gagrak lainnya, seperti wayang kulit gagrak Yogyakarta, Banyumas, Cirebon, Jawa Timur. Wayang kulit gagrak Surakarta ini memiliki proporsi fisik yang ramping dan panjang.
\end{abstract}

Kata Kunci: Wayang Kulit Purwa, Tokoh Ksatria, Gaya Surakarta

\begin{abstract}
Puppet is a cultural heritage that is Adiluhung. The greatness of philosophy and beauty of the inlaid and the art of the Puppet has gained world recognition. Purwa leather puppet, especially in the hero when observed closely, will look awesome visual detail graphic. The character value of each figure is very reflective of Javanese culture through the story in the Purwa puppet shows. In this article will be discussed about the hero and the proportion and structure of the body shape of the Surakarta-style Purwa puppet that has a characteristic or fundamental difference, among others, have a higher size one palemanan than the size of wayang kulit Other Gagrak, such as puppet skin Gagrak Yogyakarta, Banyumas, Cirebon, East Java. This Surakarta Gagrak leather puppet has slim and long physical proportions.
\end{abstract}

Keywords: Purwa puppet, knight figure, Surakarta style.

Correspondence author: Indah Nur Syahida, indahnursyahida03@gmail.com, Jakarta, and Indonesia

This work is licensed under a CC-BY-NC 


\section{PENDAHULUAN}

Wayang kulit purwa merupakan salah satu jenis wayang kulit yang cukup populer, khususnya dalam masyarakat Jawa. Kepopuleran wayang kulit purwa itu terlihat di segala lapisan masyarakat, sejak anak-anak hingga orang dewasa. Wayang kulit purwa telah dikenal sejak lama di Indonesia, setidaknya sejak abad kesepuluh, dengan sebutan ringgit. Pada waktu itu belum diketahui wujud wayang kulit purwa, tetapi cerita yang dibawakan mengambil serat Harjuna Wiwaha (Mahabarata) (Sunarto, 2006:3).

Wayang kulit purwa merupakan salah satu kesenian Jawa yang mendapat apresiasi di tingkat internasional sebagai Masterpiece of Oral and Intangible Heritage of Humanity (Susetya, 2007:8). Sebagai pertunjukan, wayang kulit mengandung integrasi seni peran, seni suara, seni musik, seni tutur, seni sastra, seni lukis, seni pahat, serta seni perlambang (Kuning, 2011).

Bahan baku yang digunakan untuk membuat wayang adalah jenis kulit binatang yang disebutnya dengan Walulang Inukir (Lulang, dalam bahasa Jawa yang diukir alau ditatah). Pada masa kebudayaan Hindu, wayang kulit mengalami perkembangan yang cukup berarti. Wujud wayang kulit mengikuti bentuk relief candi di Jawa Timur. Bentuk wayang kulit pada waktu itu diduga mirip dengan wayang kulit Bali sekarang (Sunarto, 2006:4).

Wujud visual tokoh wayang mengandung banyak makna, mulai dari raut wajah hingga kaki. Hal ini berhubungan dengan unsur perlambang, bahwa wayang bukan melambangkan fisik manusia, melainkan melambangkan watak manusia (Bastomi, 1995:9). Setiap tokoh memiliki visualisasi wajah yang berbeda. Perbedaan tersebut bisa dijadikan petunjuk dalam menentukan watak melalui bentuk mata, hidung, mulut, warna muka, serta posisi sikap wajah (Soekatno, 1992:23).

Bila kita mengamati sebuah figur wayang dari dekat, maka akan terlihat detail visual grafis yang mengagumkan. Secara anatomi, figur wayang dapat dibagi menjadi beberapa bagian yang setiap bagiannya mempunyai kekhasan aksesoris sesuai dengan karakter tokoh tersebut. Dalam Wayang Kulit Purwa terdapat beberapa tokoh yang terlibat dalam pagelaran dan pementasannya, antara lain tokoh kstaria, tokoh raja, dan tokoh putren.

Dalam artikel ini akan membahas mengenai tokoh ksatria. Tokoh wayang ksatria dibagi menjadi dua golongan, yaitu tokoh wayang Ksatria Alusan (Bokongan) dan tokoh wayang Ksatria Jangkahan (Gagahan). Cara membedakan melalui fisik antara tokoh wayang Ksatria Alusan dengan Jangkahan ialah untuk tokoh wayang Ksatria Alusan, posisi kakinya tergambar merapat tertutup oleh kain, kaki terlukis seperti orang berdiri, dan pantatnya terlihat jelas, yaitu memiliki bokongan sedangkan tokoh wayang Ksatria Jangkahan posisi kaki tergambar melebar seperti akan melangkah dan siten-siten pelemahan tampak lebih panjang (Sagio dan Samsugi, 1991:21-22).

Fokus pembahasan ini adalah mengenai proporsi dan struktur dari tokoh wayang ksatria tersebut, baik yang Tokoh Ksatria Alusan (Bokongan) maupun Tokoh Ksatria Jangkahan (Gagahan) untuk menyampaikan pesan perbedaan di antara keduanya yang dapat dilihat melalui postur tubuh pada bagian bawah khususnya, wajah, aksesoris, dan busananya.

\section{METODE PENELITIAN}

Waktu penelitian dilaksanakan secara berkala sejak bulan Maret sampai bulan Juli 2018, Solo, Jawa Tengah. Peneliti menggunakan beberapa metode yang disesuaikan, adapun data penelitian yang didapat dari hasil penelitian meliputi studi pustaka, observasi, dan wawancara.

Dari data yang didapat, peneliti menggunakan jenis penelitian kualitatif yaitu studi kepustakaan. Metode pengumpulan data menggunakan referensi buku, jurnal, dan website yang berkaitan pada materi untuk mendukung penelitian.

Observasi dilakukan secara berkala pada bulan Juni 2018 dan September 2018 degan mengamati langsung bagaimana perbedaan bentuk Tokoh Ksatria dalam dua golongan yang berbeda tersebut. Tempat penelitian dilakukan di kediaman Dr. Bambang Suwarno selaku Mpu pedalangan yang juga seniman wayang di kota Solo, Jawa Tengah.

Wawancara dilakukan dengan Bapak Dr. Bambang Suwarno, selaku Dalang dan seniman wayang kulit purwa serta pemilik dari koleksi wayang Tokoh Ksatria. Wawancara dilakukan pada kediaman beliau, di Jalan Sungai Musi, Sangkrah, Solo, Jawa Tengah. 


\section{HASIL DAN PEMBAHASAN}

\section{Wayang Kulit Purwa}

Wayang kulit purwa dikenal di Indonesia sebagai wayang dengan memiliki ciri khas yang tidak dimiliki oleh wayang lain. Wayang purwa yang dikenal saat ini telah mengalami banyak perubahan, mulai dari materi bahan yang digunakan hingga teknik perwujudannya. Asal mula seni rupa pada wayang purwa bersumber pada relief yang terdapat pada Candi Panataran di Jawa Timur, tetapi pada kenyataannya sekarang, seni rupa ini mulai berubah bentuknya dan mencapai puncak kesempurnaan pada zaman kerajaan Mataram (1586-1680) (Mulyono dalam Akbar, 2013:52)

Wayang kulit merupakan kesenian tradisional rakyat Indonesia yang mampu bertahan dan diakui eksistensinya melampaui lintas zaman dan benua. Kesenian wayang kulit meliputi seni pahat, seni lukis, seni sastra, seni tutur, seni perlambang, seni musik, seni suara, serta seni peran. Masyarakat Jawa Tengah menyebutkan bahwa 'wayang' juga dikenal dengan sebutan 'Ringgit' yang diartikan sebagai 'miring dianggit.' Miring karena wayang kulit bersikap miring, yaitu kedua bahu tangannya tidak seimbang, dengan posisi badan menghadap pada ke pemegang wayang. Dianggit artinya 'dicipta' sehingga wayang dapat digerakkan seperti orang berjalan (Marwoton Panenggak Widodo) (Salim, 2017:30).

Wujud visual wayang menyangkut penerapan seni rupa dan seni perlambang pada hampir seluruh bagian tubuh boneka wayang. Setiap tokoh wayang memiliki wujud visual yang berbeda sesuai dengan klasifikasinya. Boneka wayang kulit yang saat ini digunakan dalam pertunjukan mengalami perubahan bentuk dan wujud visual sejak zaman kerajaan Kediri (pra Majapahit) hingga kerajaan Mataram (Haryanto, 1991:30).

Penerapan seni rupa dalam wujud visual wayang dilihat dari bentuk wayang dan sunggingan serta tata warna (Suara Merdeka:2014). Bentuk wayang mencakup ukuran tubuh, penggambaran raut muka, posisi tangan, serta atribut busana. Dilihat dari ukuran tubuh, wujud visual wayang diklasifikasikan dari denawa hingga bayen. Anatomi bagian tubuh wayang juga menyimpang dari logika modern, karena dalam satu wujud tokoh wayang terdapat sudut pandang penggambaran tampak samping, depan, bawah, serta atas. Penyimpangan tersebut lebih jelasnya: 1) wajah (kecuali biji mata), dada, pinggul, lutut, dan betis digambar tampak samping; 2) bola mata, pundak, dan perut digambar tampak depan; dan 3) telapak kaki digambar tampak bawah; dan 4) jari dan kuku pada kaki digambar tampak atas (Haryanto, 1991:32).

Proses transformasi dari deskrip-si pewayangan yang divisualisasikan ke dalam bentuk figur wayang purwa disebut Wanda Wayang Purwa. Setiap tokoh wayang purwa memiliki ciri figur tersendiri, yang dalam pewayangan disebut wanda yakni bentuk secara keseluruhan dari ujung rambut sampai telapak kaki, termasuk tata busana, aksesoris, unsur garis (corekan dan kapangan) dan tata warna (sunggingan). Wujud figur wayang tidak sekadar melukiskan tokoh, tetapi juga melukiskan karakter. Pelukisan tokoh-tokoh wayang kulit purwa Jawa yang disesuaikan dengan konsep ekspresif, dekoratif, humoris, dan karikatural itu bukan mengarah pada bentuk fisik dari tokoh yang digambarkan, melainkan sifat atau karakternya. (Suwarno, 2014).

Proporsi dan struktur wayang terutama tokoh ksatria yang dikelompokan lagi dalam dua golongan, yaitu Ksatria Alusan (Bokongan) dan Ksatria Jangkahan (Gagahan) jika dilihat visualisasinya maka akan terlihat perbedaan dari keduanya, dimana tokoh wayang Ksatria Alusan, posisi kakinya tergambar merapat tertutup oleh kain, kaki terlukis seperti orang berdiri dan pantatnya terlihat jelas (Bokong), yaitu memiliki bokongan sedangkan tokoh wayang Ksatria Jangkahan yang posisi kedua kakinya melangkah, terpisah agak lebar antara kaki depan dengan kaki belakang. Kesan wayang jangkahan terlihat gagah atau siaga (Senawangi, 2017:137).

\section{Tokoh Ksatria Alusan}

Menurut bentuknya, tokoh wayang ksatria alusan adalah tokoh wayang alus, ada 2 macam alusan, yaitu alusan putran luruh (muka menunduk) yang digambarkan pada tokoh Yudhistira, Janaka, Abimanyu, Irawan, dan sebagainya yang berwatak waspada dan bijaksana. Serta alusan putran lanyap berupa bentuk muka yang tengadah. Putran lanyap (muka yang tengadah seperti melihat 
kejauhan) ini merupakan tokoh alusan yang laki-laki mempunyai watak sombong (kemaki, mbagusi), misalnya Suryaputra, Samba, Wisanggeni, Hariya Suman (Sengkuni muda), Kresna/Narayana dan sebagainya. Sikapnya yang kemaki itu kadang-kadang membawa kebijaksanaan (Supriyono 2008:5,15).

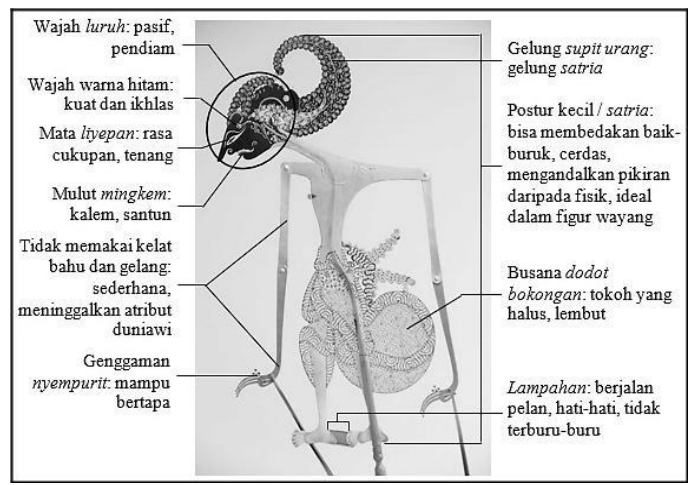

Gambar 1 Bentuk Rupa Arjuna

Wanda adalah ekspresi terutama pada wajah dan bentuk tubuh dari tokoh wayang yang mengungkapkan watak dan kepribadian dari tokoh wayang tersebut untuk mendukung suasanasuasana tertentu dalam sebuah adegan.

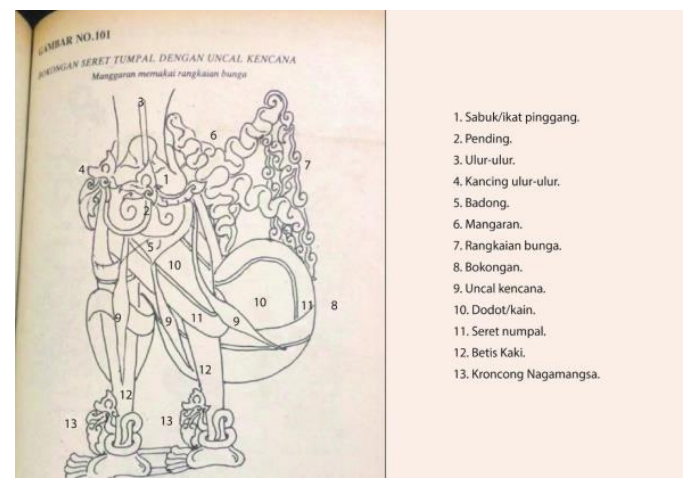

Gambar 2 Bentuk Rupa Tokoh Ksatria Alusan (Bokongan)

Dilihat dari perlengkapan wayang bagian bawah, yaitu dari perut sampai ke bawah, sebagian besar wayang memakai kain atau dodot. Wayang ini disebut Wayang Dodotan. Pakaian bagain bawah ini pada dasarnya ada dua macam, yaitu: 1) Dodotan: Memakai dodot atau kain, 2) Jubahan: Memakai jubah.

Sistim dodot ini ada beberapa macam, yaitu: 1) Dodot Kunca, untuk bentuk-bentuk wayang yang tergolong besar atau lebar langkahnya, dalam istilah wayang disebut Dugungan yaitu dari kata andungan yang berarti menyepak: Wayang yang gagah; 2) Dodotan Bokongan, yaitu sistem memakai dodot atau kain yang bentuknya seperti bokong besar, umumnya dipakai wayang golongan kecil pendek langkahnya, halus tingkahnya: Wayang yang Alus (Soekatno, 1992:120).

Wayang Ksatria Alusan (Bokongan) istilah bokongan dipakai karena bendut dodot/kain yang dipakainya dibuat seperti pantatatau bokong yang besar. Untuk menjaga keseimbangan antara dikarenakan posisi kaki yang tertutup rapat, menjajarkan keseimbangan antara kepala dan bokong. Umumnya ialah suatu bentuk wayang yang tidak besar. 


\section{Tokoh Ksatria Jangkahan}

Wayang Jangkahan ada dua macam, yaitu jangkah (langkah) yaitu Jangkah Wiyar, yaitu wayang dengan langkah lebar dan Jangkah Ciyut, yaitu wayang dengan langkah kecil. Wayang Jangkahan dengan busana bagian bawah menggunakan uncal kencana. Biasanya dikenakan oleh tokoh wayang golongan putra raja atau satria, misalnya Abimanyu, Rama, dan sebagainya.

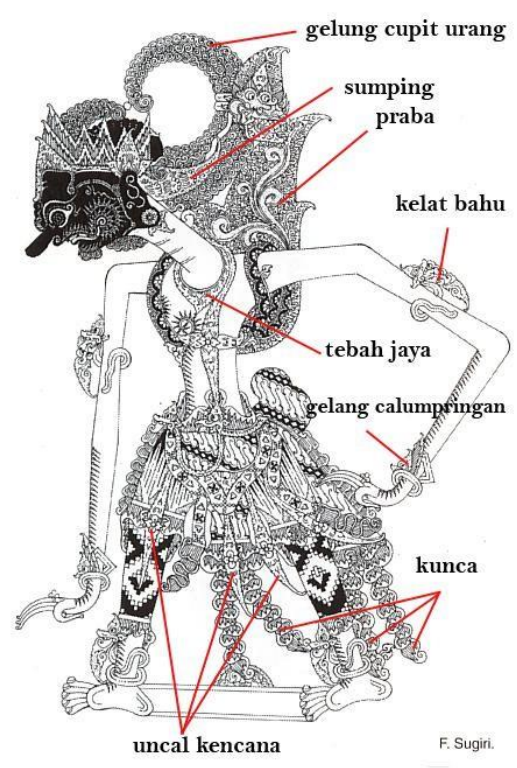

Gambar 3 Bentuk Rupa Gatotkaca

Secara umum wanda wayang merupakan kesatuan dari berbagai unsur yang terdiri dari posisi menunduk atau tengadahnya muka/wajah wayang, ukuran dan bentuk sanggul, ukuran dan bentuk mata, kondisi badan, yaitu ukuran dan posisinya, ukuran dan keseimbangan leher, sikap dan keseimbangan bahu, ukuran bentuk perut, dan busana yang dipakai.

Wayang jangkahan dengan busana bagian bawah menggunakan uncal wastra dan uncal kencana Uncal merupakan kelengkapan busana bagian bawah yang terdiri dari 2 (dua) macam, yaitu uncal kencana dan uncal wastra (wastra=selendang). Uncal kencana biasa dikenakan oleh golongan wayang satria dan golongan wayang putran (putera raja, putera pendeta, patih, dan sebagainya), serta wayang golongan raja. Wayang golongan raja jenis bokongan hanya mengenakan uncal kencana, sedangkan wayang golongan raja (Widyokusumo, 2010:404,405).

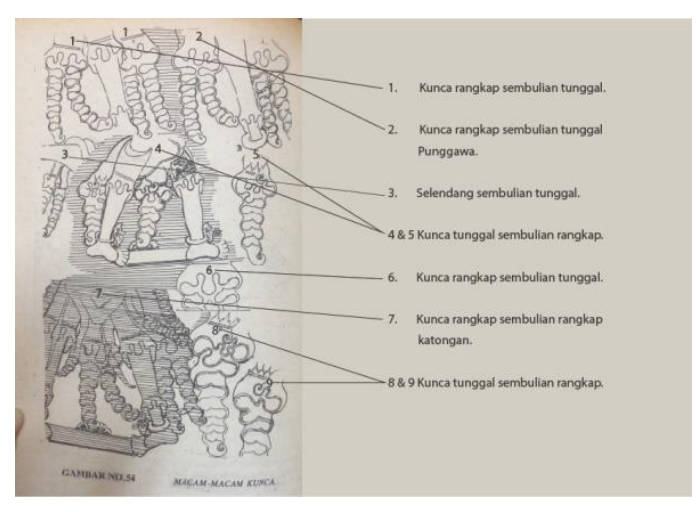

Gambar 4 Bentuk Rupa Tokoh Ksatria Jangkahan (Gagahan) 


\section{Wayang Gagrak Gaya Surakarta}

Gagrak/gaya adalah sebuah istilah, yang memiliki pengertian yaitu merupakan ciri khas dari wayang kulit yang disesuaikan dengan wilayahnya, yang pada akhirnya menjadi keaneka ragaman ciri khas bentuk, dan gagrak dipengaruhi oleh kondisi sosial, budaya, dan geografis dari wilayahnya yang memiliki perbedaan yang bertolak belakang walaupun masih dalam satu Pulau Jawa. Perbedaan ini disebabkan karena adanya penyesuaian dengan kebudayaan dilingkungan setiap wilayah sehingga memiliki karakter khusus serta menjadi ciri atau identitas kuat dari wayang kulit yang dimiliki oleh wilayah Surakarta.

Dalam pengkarakteran wayang kulit ini merupakan gagrak Surakarta yang memiliki ciri khas atau perbedaan mendasar, antara lain memiliki ukuran lebih tinggi satu palemanan daripada ukuran wayang kulit gagrak lain, seperti wayang kulit gagrak Yogyakarta, Banyumas, Cirebon, Jawa Timur. Wayang kulit gagrak Surakarta ini, memiliki proporsi fisik yang ramping dan panjang. Pada penggunaan ragam hias, akan menambah ciri khas yang akan muncul, untuk membedakan dengan gagrak wayang kulit lain seperti pada tatah sunggingnya menggunakan Hawancawarna yang artinaya berbagai macam warna.

\section{SIMPULAN}

Simpulan yang dapat diambil dari artikel ini adalah bahwa bentuk dari setiap Tokoh Wayang Kulit Purwa disesuaikan dengan konsep ekspresif, dekoratif, humoris, dan karikatural itu bukan mengarah pada bentuk fisik dari tokoh yang digambarkan, melainkan sifat atau karakternya.

Dari seluruh bagian rupa, pakaian dan perhiasan wayang kulit sudah memiliki pakem yang tidak dapat dirubah karena berkaitan dengan identitas dari tokoh tersebut, terkecuali dalam pengembangan wanda yang merubah beberapa bagian dari tokoh wayang pada dasarnya tidak merubah tampilan visual yang menjadi ciri khusus.

Setiap bentuk-bentuk wayang mempunyai arti dan makna yang dapat menjelaskan tentang suasana hati tokoh wayang, karakter wayang, penggambaran waktu dan momen pada setiap tokoh wayang. Sifat-sifat yang digambarkan dalam karakter wayang kulit purwa juga merupakan gambaran karakter-karakter manusia di dunia. Demikian juga gambaran sifat dan kehidupan tokoh perempuan dalam pergelaran Wayang Kulitt Purwa yaitu Dewi Renuka.

Untuk ikut melestarikan kebudayan wayang kulit purwa terutama karakter karakter pada berbagai macam tokoh wayang kulit purwa agar warisan budaya dapat terus dilanjutkan ke generasi selanjutnya, bagi anak Indonesia juga di harapkan untuk lebih peduli terhadap budaya penuh nilai dan makna yang kita miliki dan untuk turut bangga serta mengambil andil dalam pengembangannya.

Wayang adalah bayang-bayang kita sendiri, gambaran kehidupan kita di dunia sampai ajal menjemput. Kekayaan ragam hias dalam figur wayang kulit purwa sangat bernilai seni tinggi. Tentunya inspirasi yang bisa kita gali dari kesenian ini tak akan ada habisnya. Melalui pengetahuan akan bentuk dan ragam hias asesoris wayang diharapkan dapat menjadi sumber inspirasi kita untuk terus mempelajari, mengembangkan dan melestarikan seni budaya ini kepada generasi mendatang melalui karya-karya.

\section{DAFTAR PUSTAKA}

Senawangi. (2017). Ensiklopedia Wayang Purwa. Jakarta: PT Sakanindo Printama.

Supriyono, Admaja, D. R., Pribadi, B.S., Susilo, D. (2008). Pedalangan Jilid 1. Jakarta: Direktorat Pembinaan Sekolah Menengah Kejuruan.

Suwarno, B. (2006). Perkembangan Wayang Kulit Purwa. (Tugas Akhir). Institut Seni Indonesia Surakarta: Surakarta.

Suwarno, B. (2014). Kajian Bentuk dan Fiungsi Wanda Wayang Kulit Purwa Gaya Surakarta Kaitannya dengan Pertunjukan. Institut Seni Indonesia Surakarta: Surakarta. 
Widyokusumo, L. (2010). Kekayaan ragam hias dalam wayang kulit purwa gagrak surakarta (sebagai inspirasi desain komunikasi visual). Humaniora, 1(2), 402-414.

Akbar, T., \& Basyir, A. (2016). Asimilasi Aksara Latin dengan Tokoh Wayang Arjuna sebagai Upaya Mengenalkan Wayang Kepada Generasi Muda. Jurnal Desain, 3(02), 118-124.

Haryadi, T. H. (2014). Perancangan Model Wujud Visual Tokoh Pewayangan dalam Pembentukan Identitas dan Watak Tokoh sebagai Acuan Desain Karakter dalam Karya DKV. DeKaVe, 7(2), 58-79. 